\title{
Comparison between three types of stented pericardial aortic valves (Trivalve trial): study protocol for a randomized controlled trial
}

\author{
Kasra Azarnoush ${ }^{1,2^{*}}$, Bruno Pereira ${ }^{3}$, Christian Dualé ${ }^{4}$, Enrica Dorigo ${ }^{1}$, Mehdi Farhat ${ }^{1}$, Andrea Innorta ${ }^{1}$, \\ Nicolas Dauphin ${ }^{1}$, Etienne Geoffroy ${ }^{1}$, Pascal Chabrot $^{5}$ and Lionel Camilleri ${ }^{1}$
}

\begin{abstract}
Background: Aortic valve stenosis is one of the most common heart diseases in older patients. Nowadays, surgical aortic valve replacement is the 'gold standard' treatment for this pathology and the most implanted prostheses are biological ones. The three most implanted bovine bioprostheses are the Trifecta valve (St. Jude Medical, Minneapolis, MN, USA), the Mitroflow valve (Sorin Group, Saluggia, Italy), and the Carpentier-Edwards Magna Ease valve (Edwards Lifesciences, Irvine, CA, USA). We propose a randomized trial to objectively assess the hemodynamic performances of these bioprostheses.
\end{abstract}

Methods and design: First, we will measure the aortic annulus diameter using CT-scan, echocardiography and by direct sizing in the operating room after native aortic valve resection. The accuracy of information, in terms of size and spatial dimensions of each bioprosthesis provided by manufacturers, will be checked. Their hemodynamic performances will be assessed postoperatively at the seventh day and the sixth month after surgery.

Discussion: This prospective controlled randomized trial aims to verify and compare the hemodynamic performances and the sizing of these three bioprostheses. The data obtained may help surgeons to choose the best suitable bioprosthesis according to each patient's morphological characteristics.

Trial registration: ClinicalTrials.gov Identifier: NCT01522352

Keywords: Stented pericardial aortic valves, Pericardial aortic valves, Hemodynamic performance

\section{Background}

A critical aspect of aortic valve replacement is to achieve an optimal matching between the patient's morphology and the implanted valve prosthesis. Specifically, the implanted prosthesis should not impair left ventricle ejection and this is even more crucial in cases where there is a small aortic annulus.

Pericardial bioprostheses have good hemodynamic performance because of their central opening and the flexibility of their leaflets. We already know that the durability of these pericardial bioprostheses is about 10 to 15 years $[1,2]$.

\footnotetext{
* Correspondence: kazarnoush@chu-clermontferrand.fr

${ }^{1}$ Heart Surgery Department, Clermont-Ferrand University Hospital,

Clermont-Ferrand, France

${ }^{2}$ INRA, UMR 1019 Nutrition Humaine, F-63122 Saint Genès Champanelle, France

Full list of author information is available at the end of the article
}

At present, porcine bioprostheses are less wellperforming than bovine pericardial ones [3] and among these, we focused on three bioprostheses offering high hemodynamic performance, especially for small aortic valves.

Since March 2010, a new pericardial aortic valve bioprosthesis (Trifecta valve, St. Jude Medical, Minneapolis, MN, USA) has been approved by the Food and Drugs Administration (FDA approval: St Jude Medical Trifecta Valve - P100029) and has recently received the CE mark. However, its hemodynamic characteristics still need to be compared with other bioprostheses already available on the market. Another bioprosthesis chosen for this trial is the Mitroflow valve (Sorin Group, Saluggia, Italy) [4]: it received the CE mark in July 2011 and it is characterized by an innovative phospholipid reduction treatment (PRT)

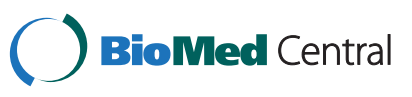


expressively conceived to reduce the calcification process and, as a consequence, to improve its durability.

The third bioprosthesis is the Carpentier-Edwards Magna Ease valve (Edwards Lifesciences, Irvine, CA, USA) which has been designed by developing the renowned and highly performing Carpentier-Edwards PERIMOUNT valves. It allows easier implantation and its pericardial tissue is additionally treated to prevent calcification. This bioprosthesis received the CE mark in 2007 and FDA approval in 2009.

\section{Objectives of the Trivalve study}

Each aortic valve has its own hemodynamic characteristics related to its geometry and each patient has their own morphology (weight, size, anatomy of aortic valve), as well as different physiological and pathophysiological conditions (ejection fraction, size and degree of calcification of the aortic annulus, degree of left ventricular hypertrophy and so on). Consequently, the choice of valve prosthesis and the surgical implantation technique are the only two directly adjustable variables; nonetheless, current literature does not provide clear differences among available bioprostheses.

The main objective of this study is to measure the hemodynamic performance of the three aortic bioprostheses: the Trifecta valve (St. Jude Medical, Minneapolis, MN, USA), the Mitroflow valve (Sorin Group, Saluggia, Italy), and the Magna Ease valve (Edwards Lifesciences, Irvine, CA, USA) Table 1.

Secondary end points will focus on 1) comparison between the effective aortic orifice area measured by computerized tomography (CT)-scan and echocardiography and the intraoperative measurement performed by a flat-head candle; 2) comparison between the diameter of the aortic orifice measured by a flat-head candle and the size of the implanted bioprosthesis provided by the manufacturer; 3) testing the accuracy of information provided by the manufacturers about bioprosthesis diameters.

\section{Methods and design}

The Trivalve trial is a single-center, prospective, randomized trial. It will evaluate the short-term (six month) hemodynamic performance of three pericardial bioprostheses: the Trifecta valve (St. Jude Medical, Minneapolis, MN, USA), the Mitroflow valve (Sorin Group, Saluggia,
Italy), and the Carpentier-Edwards Magna Ease valve (Edwards Lifesciences, Irvine, CA, USA), Figure 1.

ClinicalTrials.gov Identifier: NCT01522352.

\section{Patient's enrollment and randomization}

All patients scheduled for surgical aortic valve replacement by bioprosthesis will be screened according to inclusion and exclusion criteria (Table 2).

Patients who have given their signed informed consent to participate in this clinical trial will undergo, preoperatively, a CT-scan and a transthoracic echocardiogram to measure the aortic annulus. Included patients will be randomly allocated to receive one of the three bioprostheses, in a 1:1:1 ratio. When a patient is considered eligible and informed consent has been obtained, randomization will be performed automatically (using STATA software (StataCorp, College Station, TX, USA) before surgery by an independent biostatistician. No stratification will be done. The selected bioprosthesis will be implanted.

\section{Preoperative measurements}

Preoperative CT-scan measured data, echocardiography and surgical measurements are shown in Table 3.

\section{Surgery}

During surgery, the aortic valve of the patient will be completely removed and the aortic annulus measured using a flat-head candle. This universal candle has been specifically designed to give a single objective value of the internal diameter of the aortic annulus. The Hegar dilators will not be used as its round shape and arched aerodynamics overestimate the size of the annulus by applying opening force to its passage (Figure 2). All measurements, early postoperative complications and reoperations for bleeding will be recorded in the operative report and in the case-report form.

\section{Postoperative endpoints}

All preoperative echocardiography collected measures will be reassessed at day seven and month six after surgery in addition to maximal and mean transvalvular gradients (mmHg). ICU, total hospital stay and any other postoperative complications will be recorded in the postoperative report and in the case-report form.

Table 1 Bioprosthesis characteristics

\begin{tabular}{lll}
\hline Bioprosthesis type & Manufacturer & Valve diameters (mm) \\
\hline Trifecta & St. Jude Medical, Minneapolis, USA & 19 to 29 \\
Mitroflow & Sorin Group, Saluggia, Italy & 19 to 29 \\
Carpentier-Edwards Magna Ease & Edwards Lifesciences, Irvine, USA & 19 to 29 \\
\hline
\end{tabular}


The primary endpoint is the mean transvalvular gradient $(\mathrm{mmHg})$ six months after surgery. All secondary endpoints are indicated in Table 4.

\section{Statistical considerations Sample size estimation}

The estimation of the number of patients required was considered by using previous data provided by the manufacturers on patients who had cardiovascular surgery which showed the mean postoperative gradients $(\mathrm{mmHg})$ for the three studied types of valve (data not published). A minimum difference $(\delta)$ of $4 \mathrm{mmHg}$ could be expected between the three types of valve for the most relevant diameters (21 and $23 \mathrm{~mm}$ ). As the information concerning statistical variability was not provided in this document, the standard deviation $(\sigma)$ was estimated on the basis of data from 103 patients observed in our center (84 with the Edwards Ease prosthesis, 19 with a Mitroflow diameter of 21 or $23 \mathrm{~mm}$ ): $\sigma=5.8$. Thus, for a type 1 error $\alpha=0.05$ (two-sided), a $90 \%$-power, $\delta=4$ and $\sigma=5.8,44$ subjects per group are needed. Taking into account multiple comparisons between the three randomized groups, 55 patients per group will be included (165 patients in total).

\section{Statistical analyses}

All analyses will be performed using STATA v11 (StataCorp, College Station, TX, USA). A two-tailed $P$-value of 0.05 will be considered statistically significant. All analyses will be performed on an intention-to-treat (ITT) basis. The number of included patients and the rate of inclusions will be presented over time for each 
Table 2 Inclusion and exclusion criteria

\begin{tabular}{|c|c|}
\hline \multirow[t]{2}{*}{ Inclusion criteria } & $\begin{array}{l}\text { Isolated aortic valve replacement or associated } \\
\text { with myocardial revascularization and/or tricuspid } \\
\text { valve repair }\end{array}$ \\
\hline & Age ( $>18$ years and $<85$ years) \\
\hline \multirow[t]{16}{*}{ Exclusion criteria } & Emergency surgery \\
\hline & Surgery other than full sternotomy \\
\hline & Heart transplantation \\
\hline & $\begin{array}{l}\text { Any procedure involving the aorta (such as Bentall } \\
\text { procedure, surgery for dissection, and so on) }\end{array}$ \\
\hline & Redo surgery \\
\hline & Active infective endocarditis \\
\hline & Associated mitral valve surgery \\
\hline & $\begin{array}{l}\text { Heart failure (ejection fraction }<40 \% \text { ) or } \\
\text { preoperative cardiogenic shock }\end{array}$ \\
\hline & Systolic pulmonary arterial pressure $>60 \mathrm{mmHg}$ \\
\hline & Patient's protocol refusal \\
\hline & Pregnancy \\
\hline & $\begin{array}{l}\text { Mentally handicapped patients, pre-existing } \\
\text { psychiatric disease or addiction }\end{array}$ \\
\hline & $\begin{array}{l}\text { Advanced respiratory failure (forced expiratory } \\
\text { volume in } 1 \text { second or vital capacity below } \\
50 \% \text { of the predicted) }\end{array}$ \\
\hline & Severe renal failure \\
\hline & $\begin{array}{l}\text { History of allergy or intolerance to iodinated } \\
\text { contrast infusion }\end{array}$ \\
\hline & $\begin{array}{l}\text { Patients living more than } 100 \mathrm{~km} \text { away from } \\
\text { the investigation center }\end{array}$ \\
\hline
\end{tabular}

group. The patients will be described and compared between groups at baseline according to the following variables: compliance with eligibility criteria, epidemiological features, clinical features (including echocardiographic) and biological characteristics. The comparison concerning the postoperative means of the transvalvular gradients (measured by echocardiography at six months post surgery) between the three groups will be evaluated using ANOVA followed by the Tukey-Kramer post hoc test, or the Kruskal-Wallis nonparametric test if conditions of ANOVA are not met (homoscedasticity studied by Bartlett's test and normality verify by Shapiro-Wilk) followed by Dunn's test as appropriate. Comparisons between the groups will be realized systematically 1) without adjustment and 2) when appropriate, after adjustment (by multivariate linear regression model) on factors whose distribution could be unbalanced between the arms despite randomization. Quantitative secondary endpoints (for example hemodynamic data, CT-scan, inhospital stay) will be analyzed as described above. Categorical parameters (that is, proportion of reoperations) will be compared between the groups using the chisquared test or Fisher's exact test, when necessary. To assess the relationships between the quantitative parameters
Table 3 CT-scan, echocardiographic and surgical measurements

\begin{tabular}{|c|c|c|c|c|}
\hline & $\begin{array}{l}\text { Preoperative } \\
\text { data }\end{array}$ & $\begin{array}{l}\text { Operative } \\
\text { data }\end{array}$ & $\begin{array}{l}\text { Day } \\
7 \text { data }\end{array}$ & $\begin{array}{l}\text { Month } \\
6 \text { data }\end{array}$ \\
\hline \multicolumn{5}{|l|}{ CT-scan } \\
\hline Native aortic annulus (mm) & $x$ & & & \\
\hline $\begin{array}{l}\text { Ascending aorta } \\
\text { diameter }(\mathrm{mm})\end{array}$ & $x$ & & & \\
\hline \multicolumn{5}{|l|}{ Echocardiography } \\
\hline LVTS (mm) & $x$ & & $x$ & $x$ \\
\hline LVTD (mm) & $x$ & & $x$ & $x$ \\
\hline LVPWT (mm) & $x$ & & $x$ & $x$ \\
\hline IVST (mm) & $x$ & & $x$ & $x$ \\
\hline LVSF (\%) & $x$ & & $x$ & $x$ \\
\hline LVEF (\%) & $x$ & & $x$ & $x$ \\
\hline Pulmonary arterial pressure & $x$ & & $x$ & $x$ \\
\hline Cardiac output (L/min $\left.{ }^{-1}\right)$ & $x$ & & $x$ & $x$ \\
\hline Cardiac index $\left(\mathrm{L} / \mathrm{min}^{-1} / \mathrm{m}^{-2}\right)$ & $x$ & & $x$ & $x$ \\
\hline $\begin{array}{l}\text { Mean transvalvular } \\
\text { gradient }(\mathrm{mmHg})\end{array}$ & $x$ & & $x$ & $x$ \\
\hline $\begin{array}{l}\text { Maximal transvalvular } \\
\text { gradient }(\mathrm{mmHg})\end{array}$ & $x$ & & $x$ & $x$ \\
\hline Aortic orifice area $\left(\mathrm{m}^{2}\right)$ & $x$ & & $x$ & $x$ \\
\hline $\begin{array}{l}\text { Aortic regurgitation } \\
\text { degree }(0-4)\end{array}$ & $x$ & & $x$ & $x$ \\
\hline Paravalvular leak & & & $x$ & $x$ \\
\hline \multicolumn{5}{|l|}{ Surgery } \\
\hline $\begin{array}{l}\text { Internal aortic annulus } \\
\text { diameter (mm) }\end{array}$ & & $x$ & & \\
\hline $\begin{array}{l}\text { Estimated valve } \\
\text { diameter (mm) }\end{array}$ & & $x$ & & \\
\hline $\begin{array}{l}\text { Implanted valve } \\
\text { diameter (mm) }\end{array}$ & & $x$ & & \\
\hline
\end{tabular}

IVST: inter ventricular septum thickness, LVEF: left ventricular ejection fraction, LVPWT: left ventricle posterior wall thickness, LVSF: left ventricular shortening fraction, LVTD: left ventricle tele diastolic diameter, LVTS: left ventricle tele systolic diameter.

(comparison between aortic orifice measurements by echocardiography, CT-scans, intraoperative measurement using the flat- candle versus the size of implanted valve prosthesis given by the manufacturer), the correlation coefficients (Pearson or Spearman), the Lin concordance coefficient and the intra-class coefficient (ICC) will be calculated. Later on, an ANCOVA could be proposed to consider group effect. The intra-group comparisons related to the quantitative criteria (hemodynamic data by echocardiography on preoperative period and at six months) will be made using paired the ANOVA or Wilcoxon test. Finally, to avoid bias induced by the presence of missing data, particularly with regards to the mean postoperative transvalvular gradient at six months (lost at follow-up or deaths), the primary analysis (ITT 


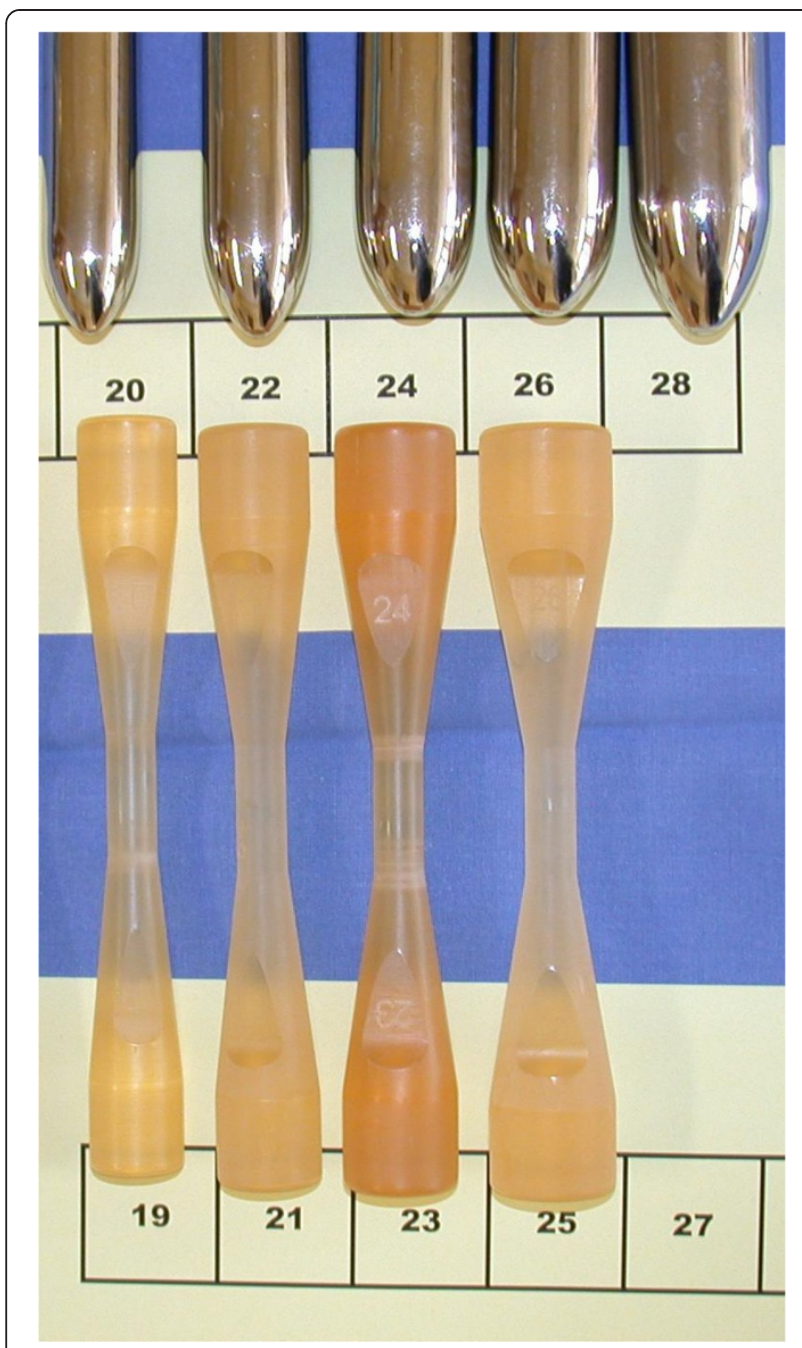

Figure 2 Importance of the use of flat-head candles to measure the aortic ring (bottom of the picture) compared to Hegar dilators.

\section{Table 4 Primary and secondary endpoints}

\begin{tabular}{|c|c|}
\hline Primary endpoint & $\begin{array}{l}\text { Mean transvalvular gradient }(\mathrm{mmHg}) \text {, six months } \\
\text { after surgery }\end{array}$ \\
\hline \multirow[t]{4}{*}{ Secondary endpoints } & $\begin{array}{l}\text { Effective aortic orifice diameter measured by } \\
\text { CT-scan and echocardiography compared with } \\
\text { the surgical data (mm) }\end{array}$ \\
\hline & $\begin{array}{l}\text { Mean transvalvular gradient }(\mathrm{mmHg}) \text {, at day } \\
\text { seven after surgery }\end{array}$ \\
\hline & $\begin{array}{l}\text { Aortic bioprosthesis orifice area }\left(\mathrm{m}^{2}\right) \text {, six months } \\
\text { after surgery }\end{array}$ \\
\hline & $\begin{array}{l}\text { Diameter of the aortic orifice measured by a } \\
\text { flat-head candle compared with the size of the } \\
\text { implanted bioprosthesis ( } \mathrm{mm})\end{array}$ \\
\hline
\end{tabular}

with imputation data determined according to quantity and type of missing data) will be completed on a second time by a per-protocol analysis.

\section{Expected adverse events}

These three prosthetic valves are made of three layers of fixed bovine pericardium assembled on a support (stent). They are then fixed in a glutaraldehyde solution and conditioned in a sterile manner. A correctly sized and implanted valve leads to very few complications. They have an average lifespan of $>10$ years when implanted in patients aged $>65$ years $[1,2]$. The expected adverse events of these bioprostheses are those of usual heart valve replacement surgery on cardiopulmonary bypass and mortality can be predicted by Euroscore 2 [5], which is systematically calculated for all our patients. Postoperative adverse events will be evaluated according to the ClavienDindo classification for surgical complications [6].

\section{Funding}

Edwards Lifesciences (Irvine, CA, USA), St. Jude Medical (Minneapolis, MN, USA), and Sorin Group (Saluggia, Italy) gave a contribution of $€ 5,000$ each and the Hospital Clinical Research Program (PHRC) of the French Ministry of Health contributed an amount of $€ 15,000$ for the realization of this study.

\section{The status of this trial}

This trial has been actively recruiting patients since March 2012. The French Committee on Human Research (CPP Sud-Est VI) consented to this trial on 17 January 2012. Patients give their informed consent before being enrolled in this study. Agreement from the French Competent Authority (ANSM) was obtained on 23 June 23 2011. The completion date for this study is estimated as December 2014. The ClinicalTrials.gov identifier is NCT01522352.

\section{Discussion}

Several studies have emphasized the importance of valve prosthesis hemodynamic performance $[7,8]$, but none has taken into account more than one or two bioprostheses at a time $[9,10]$. Thus, we strongly believe that a randomized trial, with no direct conflicts of interest with industry, is mandatory to compare the three bioprostheses most commonly implanted in France and all around the world.

Our secondary objective is to compare the reliability of preoperative CT-scan and echocardiography used to assess the size of the aortic annulus in comparison to the surgical measurement. Both techniques (CT-scans and echocardiography) are already successfully used to predict the correct size of the aortic annulus before trans-catheter valve implantation procedures [11]. Another secondary 
objective, once we have assessed the surgical diameter of the aortic annulus intraoperatively, is to verify the reliability of the prosthesis size provided by the manufacturer. This last point is interesting as it aims to clarify an issue often debated by surgeons who complain to manufacturers that they over- or underestimate valve sizes. Precise information on the size of the implanted bioprosthesis compared to the real dimensions of the aortic annulus will guide cardiac surgeons to choose between these three bioprostheses according to the patient's morphological characteristics.

\section{Abbreviations}

ANSM: Agence nationale de sécurité du médicament; CE: Conformité Européenne; CPP: Comité de protection des personnes; CT: Computerized Tomography; FDA: Food and drugs administration; ICC: Intra-class coefficient; ITT: Intention-to-treat; mmHg: Millimeter of mercury; PRT: Phospholipid reduction treatment.

\section{Competing interests}

The authors declare that they have no competing interests other than mentioned in this manuscript. Edwards Lifesciences (Irvine, CA, USA), St. Jude Medical (Minneapolis, MN, USA), and Sorin Group (Saluggia, Italy) gave a contribution of $€ 5000$ each and the Hospital Clinical Research Program (PHRC) of the French Ministry of Health contributed an amount of $€ 15,000$ for the realization of this study.

\section{Authors' contributions}

KA: conception, design, surgical management and writing of the manuscript. BP: conception, design and statistical management. CD: conception, design and statistical management. ED: critical revisions of the manuscript. MF: conception, design and surgical management. Al: conception, design and surgical management. ND: conception, design and echocardiography. EG: conception, design and echocardiography. PC: conception, design and CT-scan. LC: conception, design, surgical management, critical revisions and final approval. All authors read and approved the final manuscript.

\section{Acknowledgement}

The authors acknowledge the French Ministry of Health, Edwards Lifesciences (Irvine, CA, USA), St. Jude Medical (Minneapolis, MN, USA), and Sorin Group (Saluggia, Italy) for their financial support. They also thank Ms. Valérie Batel and all patients participating in this trial for their valuable help.

\section{Author details}

${ }^{1}$ Heart Surgery Department, Clermont-Ferrand University Hospital, Clermont-Ferrand, France. ${ }^{2}$ INRA, UMR 1019 Nutrition Humaine, F-63122 Saint Genès Champanelle, France. ${ }^{3}$ Biostatistics Unit, Délégation Recherche Clinique \& Innovation, Clermont-Ferrand University Hospital, Clermont-Ferrand, France. ${ }^{4}$ Centre de Pharmacologie Clinique (Inserm CIC 501), Clermont-Ferrand University Hospital, Clermont-Ferrand, France.

${ }^{5}$ Radiology Department, Clermont-Ferrand University Hospital, Clermont-Ferrand, France.

Received: 30 July 2013 Accepted: 25 November 2013 Published: 3 December 2013

\section{References}

1. McClure RS, Narayanasamy N, Wiegerinck E, Lipsitz S, Maloney A, Byrne JG, Aranki SF, Couper GS, Cohn LH: Late outcomes for aortic valve replacement with the Carpentier-Edwards pericardial bioprosthesis: up to 17-year follow-up in 1,000 patients. Ann Thorac Surg 2010, 89(5):1410-1416.

2. Yankah CA, Pasic M, Musci M, Stein J, Detschades C, Siniawski H, Hetzer R: Aortic valve replacement with the Mitroflow pericardial bioprosthesis: durability results up to 21 years. J Thorac Cardiovasc Surg 2008, 136(3):688-696.

3. Chambers JB, Rajani R, Parkin D, Rimington HM, Blauth $\mathrm{Cl}$, Venn $\mathrm{GE}$, Young $C P$, Roxburgh JC: Bovine pericardial versus porcine stented replacement aortic valves: early results of a randomized comparison of the Perimount and the mosaic valves. J Thorac Cardiovasc Surg 2008, 136(5):1142-1148.

4. Walker DK, Scotten LN, Brownlee RT: The Mitroflow pericardial heart valve. In vitro assessment over a range of sizes in aortic and mitral positions. Scand J Thorac Cardiovasc Surg 1985, 19(2):131-138.

5. Nashef SA, Roques F, Sharples LD, Nilsson J, Smith C, Goldstone AR, Lockowandt U: EuroSCORE II. Eur J Cardiothorac Surg 2012, 41(4):734-744.

6. Dindo D, Demartines N, Clavien PA: Classification of surgical complications. Ann Surg 2004, 240(2):205-213.

7. Dalmau MJ, González-Santos JM, Blázquez JA, et al: Hemodynamic performance of the Medtronic mosaic and Perimount magna aortic bioprostheses: five-year results of a prospectively randomized study. Eur J Cardiothorac Surg 2011, 39(6):844-852.

8. Tasca G, Brunelli F, Cirillo M, et al: Impact of valve prosthesis-patient mismatch on left ventricular mass regression following aortic valve replacement. Ann Thorac Surg 2005, 79(2):505-510,

9. Totaro P, Degno N, Zaidi A, Youhana A, Argano V: Carpentier-Edwards PERIMOUNT Magna bioprosthesis: a stented valve with stentless performance? J Thorac Cardiovasc Surg 2005, 130(6):1668-1674.

10. Suri RM, Michelena HI, Burkhart HM, et al: A prospective, randomized comparison of three contemporary bioprosthetic aortic valves: should hemodynamic performance influence device selection? I Thorac Cardiovasc Surg 2012, 144(6):1387-1395.

11. Tzikas A, Schultz CJ, Piazza N: Assessment of the aortic annulus by multislice computed tomography, contrast aortography, and transthoracic echocardiography in patients referred for transcatheter aortic valve implantation. Catheter Cardiovasc Interv 2011, 77(6):868-875.

doi:10.1186/1745-6215-14-413

Cite this article as: Azarnoush et al:: Comparison between three types of stented pericardial aortic valves (Trivalve trial): study protocol for a randomized controlled trial. Trials 2013 14:413.

\section{Submit your next manuscript to BioMed Central and take full advantage of:}

- Convenient online submission

- Thorough peer review

- No space constraints or color figure charges

- Immediate publication on acceptance

- Inclusion in PubMed, CAS, Scopus and Google Scholar

- Research which is freely available for redistribution 